\title{
The Growth Rate of Balanus hameri (Ascanius).
}

\author{
By \\ Hilary B. Moore, Ph.D., \\ Marine Biological Laboratory, Plymouth. \\ With 4 Figures in the Text. \\ Material.
}

In December, 1933, a cluster of Balanus hameri which had been taken by fishermen on long lines set for cod in twenty-five fathoms on the outer edge of Bank Charles, about four miles south of Spanish Head, in the Isle of Man, was sent in to the Biological Station at Port Erin. The species appears to be fairly common in that locality. The cluster had started as a single barnacle, on which others had settled, and others again on these, up to, apparently, five successive broods. In all there were sixty barnacles in the cluster, and the present paper comprises an analysis of their size in an attempt to arrive at their growth rate.

In addition to the above material there was another cluster preserved in alcohol in the station museum, but unfortunately without a date. The latter was, however, known to be about 1925, and must have been between December and March, these being the limits of the cod fishery on that ground. This also was confirmed by the presence of early larvæ in the mantle cavities, while all the 1933 material was ripe but unspawned.

\section{Methods.}

Each cluster was drawn, and the individual barnacles were numbered. The opercular plates of each were then removed, and the scutum measured. A representative series of animals were removed from their shells and fixed in Bouin's fluid for sectioning. The whole cluster was then boiled for a few minutes and cleaned out, after which it was oven dried. The internal volume of each barnacle was measured by filling its shell with water from a graduated burette, and in a series of specimens the external volume also was estimated by displacement after the shell had been filled with paraffin wax.

\section{Size Distribution.}

It was hoped that the length of the scutum might afford a reliable measure of the size of this animal which changes so greatly in shape during 
its life, but this was found not to be the case. In practice the volume of the barnacle was found to be a much more satisfactory measure of size, and in the size distribution curves, the cube root of the volume is taken as a linear measure of size. The size distribution data for the two sets of material are given in Table I, and those from fifty-four specimens of the 1933 material in Figure 1. The other six specimens of this series were either removed whole for sectioning or damaged. The curve for the 1933 material shows peaks at sizes of $0 \cdot 1,0.65$ and $1 \cdot 3 \mathrm{~cm}$., approximately

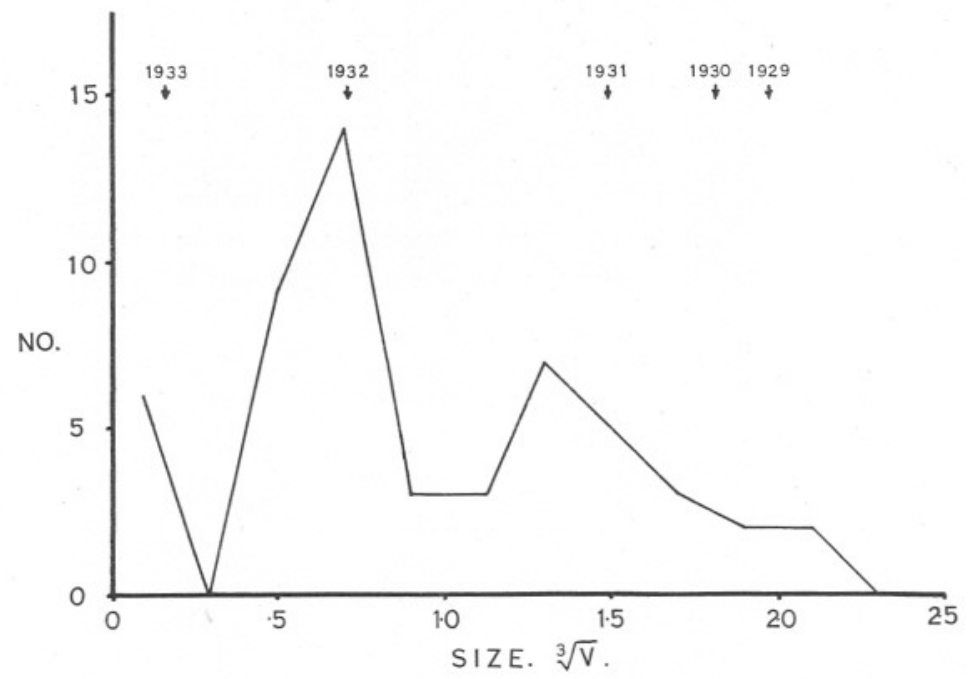

Fig. 1.-Size distribution of 1933 material. Arrows indicate mean year group sizes as obtained from successively settled broods.

$\left({ }^{3} \sqrt{\mathrm{V}}\right)$. The 1925 sample shows peaks at about $0 \cdot 4,0.9$ and $1.3 \mathrm{~cm}$., the increased size at which the peaks occur probably representing growth between the seasons of the two samples, but the number of available specimens is too small to be certain of this.

\section{Successive Broods.}

If, as is almost certainly the case, the barnacles reproduce only once in the year, then it may be taken that where one barnacle is found settled on a larger one, the latter must be at least a year older than the former. Exceptions occur where an individual has, in the course of its growth, been pushed from its original position by another barnacle, but it is usually obvious when this has happened. In Figures 2 and 3 the 1933 cluster has been divided into two, and for the sake of simplicity, a part only of each cluster has been drawn. To begin with, there were on No. 24 
a number of very small individuals (not visible in the figure) corresponding to the size of the first peak in Figure 1. Some of these were removed whole for sectioning, and hence are not included in the table of size distribution. More of this size are scattered throughout the cluster, and one of them

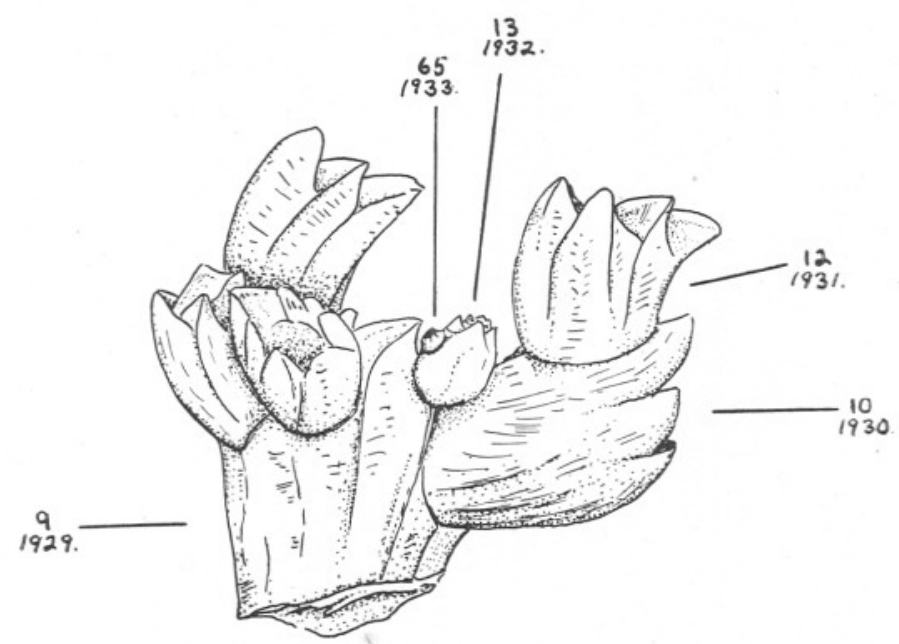

FIg. 2.-Portions of colony of B. hameri $(1933$ material) $\times 1$.

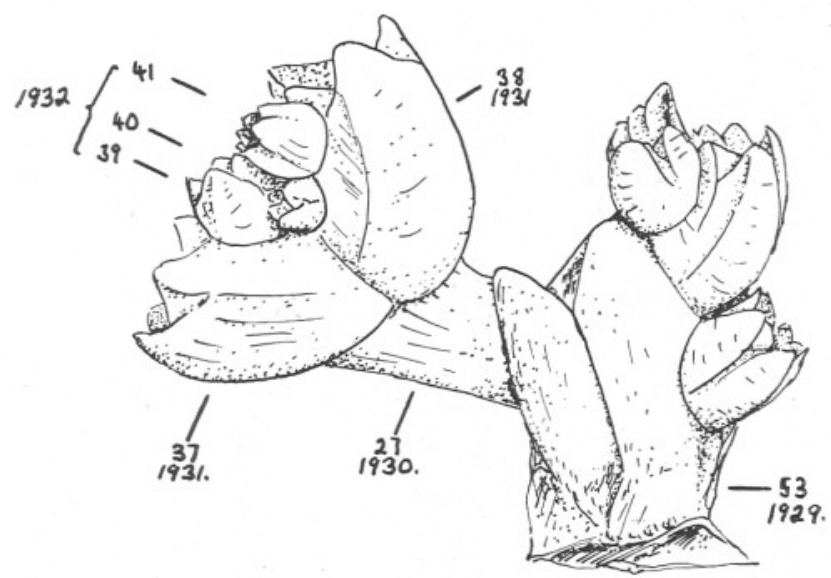

FIG. 3.-Portions of colony of B. hameri (1933 material) $\times 1$.

(No. 65) is settled on No. 13 (Fig. 2) which has a size $(\sqrt[3]{ } \bar{V})$ of $0.57 \mathrm{~cm}$., and is thus dated, together with the rest of the barnacles comprising the second peak, as being of the 1932 group. This, of course, is on the assumption that no year group is completely unrepresented in the cluster. The 
bulk of the 1932 peak is derived from a number of specimens (39, 40, 41, etc., Fig. 3), all of about the same size as No. 13, and clearly all of last year's hatching. The larger barnacles (Nos. 28, 29, 37, 38, 49, etc.) on which this 1932 group is clustered, also fall into a single size group agreeing with the third peak in Figure 1, and dating this as the 1931 group. This group is settled round No. 27 which must therefore be dated 1930, and this in turn is growing on No. 53 which must be 1929. A similar sequence is afforded by Nos. 12, 10 and 9 (Fig. 2), the latter being settled alongside No. 53 on a still larger barnacle which was dead when taken.

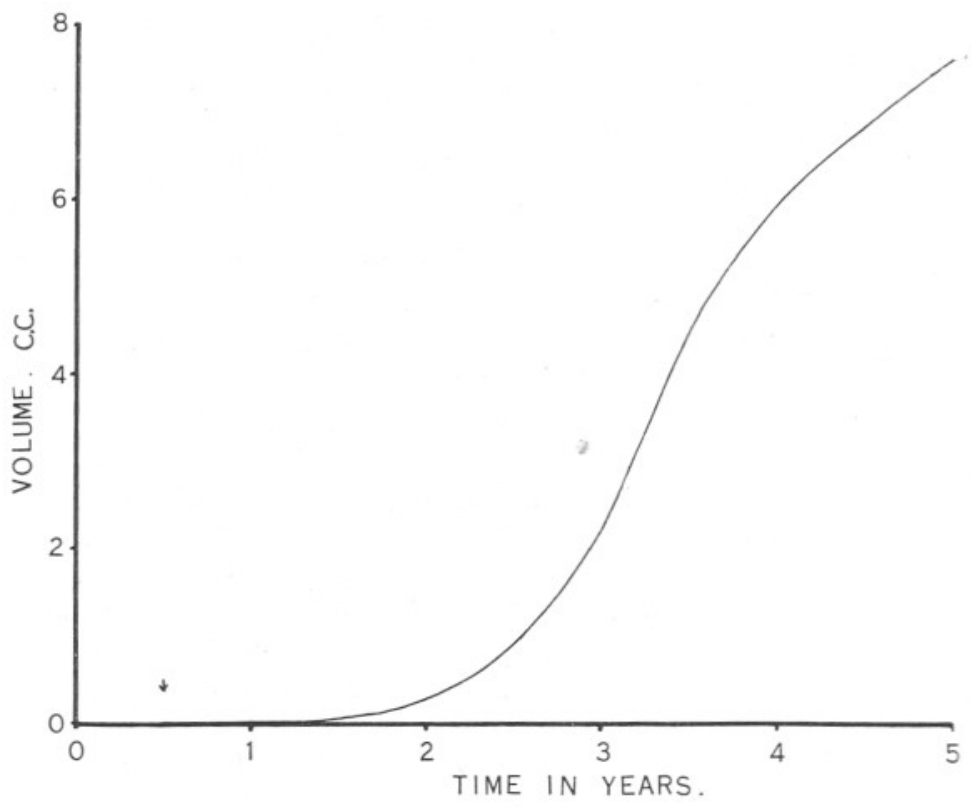

FIG. 4.-Growth of B. hameri.

The results for all those animals whose age can be determined in this way are brought together in Table II, and they yield group mean volumes as follows : $1933,0 \cdot 04$ c.c. ; $1932,0 \cdot 26$ c.c. ; $1931,3 \cdot 29$ c.c. ; $1930,5 \cdot 90$ c.c. ; $1929,7 \cdot 67$ c.c. The sizes $\left({ }^{3} \sqrt{\mathrm{V}}\right)$ corresponding to these are shown by arrows in Figure 1, and are seen to agree well with the size distribution peaks.

In Figure 4 are plotted the volumes in relation to age, taking the data from Table I for the first three years, and those from Table II for the succeeding years, as being more accurate. The biggest barnacle measured in this material had a volume of 17 c.c., and a probable age of 8 or 9 years (1925 material), but probably even larger sizes may be attained on this ground. A specimen taken growing on Keppel Pier in the Clyde had a scutum length of $29.4 \mathrm{~mm}$., a height of $5.7 \mathrm{~cm}$., and an external volume of 
about 45 c.c. Finally, for comparison of these results with those for other species of Balanus in which it has been possible to measure external volumes only, the following ratio was obtained from a series of specimens of $B$. hameri, $\frac{\text { External volume }}{\text { Internal volume }}=1 \cdot 5$.

\section{Condition of the Gonads.}

Of the material collected in December, 1933, twenty individuals were sectioned, comprising two first year, seven second year, nine third, one fourth and two fifth-year barnacles. In the first-year (1933) individuals no development of the gonad, either ovary or testis, was discernible. Considering the condition of the gonads in older individuals, it may therefore be said that this species does not spawn in its first season. In the second year group all individuals examined had testicular cæcæ full of ripe spermatozoa together with developing spermatocytes, and the vesiculæ seminales also were full of sperm. The ovaries were medium sized, and contained a few large, and numerous smaller ova. All the older individuals were in the same condition except for the much greater development of their ovaries, which in the old deep-shelled specimens reached a very large size. By comparison with the gonads of Balanus balanoides (Moore, 1934), it would seem that shedding of the genital products into the mantle cavity, and fertilisation, would probably have taken place within two or three months at most. The 1925 material showed early larvæ in the mantle cavities of all the mature specimens, thus again indicating shedding of the genital products into the mantle cavity some time between December and March. This is later than in the case of B. balanoides from the Isle of Man, where fertilisation usually takes place about November.

\section{SUMMARY.}

1. Sixty specimens of B. hameri, of five successive year groups, were obtained in December, 1933, and a further 33 preserved specimens taken in the winter of 1925 were examined.

2. The mean ages contained for successive year groups from the size distribution and from individuals settled on those of the preceding year, yielded results in good agreement with one another.

3. First-year individuals do not spawn. All older individuals had ripe genital products in the 1933 material, and early embryos in the 1925 material. 


\section{REFERENCE.}

Moore, H. B. 1934. The Biology of Balanus balanoides. I. Growth Rate and its Relation to Size, Season and Tidal Level. Journ. Mar. Biol. Assoc., N.S., Vol. XIX, No. 2, p. 851.

\section{TABLE I.}

Size Distributions of the 1925 and 1933 Material in Terms of Cube Root of Volume.

Read to the nearest $0 \cdot 2 \mathrm{~cm}$.

$\begin{array}{ccc}\text { Size. } & 1925 & \text { Number } \\ 0 \cdot 1 & 0 & 1933 \\ 0 \cdot 3 & 4 & 6 \\ 0 \cdot 5 & 2 & 0 \\ 0 \cdot 7 & 3 & 9 \\ 0 \cdot 9 & 6 & 14 \\ 1 \cdot 1 & 2 & 3 \\ 1 \cdot 3 & 6 & 3 \\ 1 \cdot 5 & 1 & 7 \\ 1 \cdot 7 & 2 & 5 \\ 1 \cdot 9 & 1 & 3 \\ 2 \cdot 1 & 0 & 2 \\ 2 \cdot 3 & 2 & 2 \\ 2 \cdot 5 & 1 & 0 \\ 2 \cdot 7 & 0 & 0 \\ & 0 & 0\end{array}$


TABLE II.

Data from Successively Settled Broods.

\begin{tabular}{|c|c|c|c|c|c|c|c|}
\hline & & & & & & & \\
\hline $\begin{array}{l}\text { Year } \\
\text { group. }\end{array}$ & $\begin{array}{l}\text { Specimen } \\
\text { No. }\end{array}$ & $\begin{array}{l}\text { Tergum } \\
\text { length } \\
\text { mm. }\end{array}$ & $\begin{array}{l}\text { Tergum } \\
\text { length } \\
\text { mm. }\end{array}$ & $\begin{array}{l}\text { Internal } \\
\text { volume } \\
\text { c.c. }\end{array}$ & $\begin{array}{l}\text { Internal } \\
\text { volume } \\
\text { c.c. }\end{array}$ & $\begin{array}{l}\sqrt{\text { mean vol. }} \\
\text { c.c. }\end{array}$ & $\begin{array}{l}\text { No. of } \\
\text { speci- } \\
\text { mens. }\end{array}$ \\
\hline 1933 & 65 & $3 \cdot 2$ & $3 \cdot 2$ & 0.04 & 0.04 & $0 \cdot 16$ & 1 \\
\hline & 13 & $7 \cdot 07$ & & $(0 \cdot 20)$ & & & \\
\hline & 20 & $6 \cdot 6$ & & $0 \cdot 15$ & & & \\
\hline & 39 & $9 \cdot 0$ & & $0 \cdot 37$ & & & \\
\hline & 40 & $5 \cdot 1$ & & - & & & \\
\hline & 41 & $7 \cdot 0$ & & $0 \cdot 68$ & & & \\
\hline 1932 & 43 & $3 \cdot 9$ & $6 \cdot 6$ & $0 \cdot 11$ & $0 \cdot 26$ & $0 \cdot 71$ & 11. \\
\hline & 44 & 6.5 & & $0 \cdot 28$ & & & \\
\hline & 45 & $8 \cdot 0$ & & $0 \cdot 43$ & & & \\
\hline & 47 & $6 \cdot 6$ & & $0 \cdot 28$ & & & \\
\hline & 50 & 6.9 & & $0 \cdot 25$ & & & \\
\hline & 51 & $6 \cdot 5 \mathrm{~J}$ & & $0 \cdot 25]$ & & & \\
\hline & $(12$ & $16 \cdot 37$ & & $(2.85)$ & & & \\
\hline & 28 & 16.9 & & 3.55 & & & \\
\hline 1931 & 29 & $15 \cdot 4$ & 16.5 & $2 \cdot 50$ & 3.99 & 1.49 & 6 \\
\hline 1951 & 37 & $18 \cdot 0$ & & $4 \cdot 05$ & 5 & 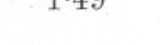 & 0 \\
\hline & 38 & $18 \cdot 9$ & & $5 \cdot 10$ & & & \\
\hline & 49 & $13 \cdot 6 \mathrm{~J}$ & & $(1.70)$ & & & \\
\hline 1930 & $\{10$ & $18 \cdot 0\}$ & $17 \cdot 8$ & $\{6 \cdot 10\}$ & $5 \cdot 90$ & 1.89 & 2 \\
\hline 1930 & 27 & $17.5\}$ & 18.8 & $\{5 \cdot 70\}$ & 5.90 & 1.09 & \\
\hline 1929 & $\left\{\begin{array}{r}9 \\
53\end{array}\right.$ & $\left.\begin{array}{l}21 \cdot 7 \\
20 \cdot 7\end{array}\right\}$ & $21 \cdot 2$ & $\left\{\begin{array}{l}7 \cdot 25 \\
8 \cdot 10\end{array}\right\}$ & $7 \cdot 67$ & $1 \cdot 97$ & 2 \\
\hline
\end{tabular}


